\title{
Towards an Internalist Conception of Justification in African Epistemology
}

Adebayo A. Ogungbure

Department of Philosophy

University of Ibadan, Nigeria

bavo.ogungbure@gmail.com

DOI: $\underline{\text { http://dx.doi.org/10.4314/tp.v6i2.4 }}$

Thought and Practice: A Journal of the Philosophical Association of Kenya (PAK) New Series, Vol.6 No.2, December 2014, pp.39-54

thoughtandpractice@gmail.com

http://ajol.info/index.php/tp/index

ISSN: 2076-7714 


\begin{abstract}
In current discussions on African epistemology, the issue of justification of beliefs has mainly been considered from an externalist perspective, such that justification is described as achievable merely through the means of empirical verification and social context of discourse. However, this results in a knowledge-gap since both internalist and externalist perspectives are needed to arrive at a holistic notion of epistemic justification. Consequently, the objective of this article is to fill this gap by employing the methods of conceptual and critical analysis to attempt an internalist interpretation of epistemic justification in the quest for a more balanced view of African epistemology.
\end{abstract}

\title{
Key Words
}

Internalism, African Epistemology, African Beliefs, Justification

\section{Introduction}

There has been an extensive debate in contemporary epistemology on whether grounds for justifying beliefs are internal or external (Sosa 1991; Kihyeon 1993; Marvan 2006). While internalists hold that what confers justification must be "within" the subject in that he or she must have a direct cognitive access to it, externalists posit that factors outside of the agent's mind can affect the justificatory status of a belief. However, when the fabric of this debate is considered in relation to recent discussions on African epistemology, we begin to notice a one-sided discourse, because the grounds offered for the justification of beliefs are deeply immersed in an externalist outlook. Thus this article should be seen as a preliminary attempt to fill this knowledge-gap by explicating the internalist framework of justification in African epistemology.

More specifically, this article aims to highlight the relevance of the internalist-externalist debate in Western epistemology to the African epistemological perspective. It identifies the prevalent notion of justification in African epistemology as externalist; but it goes on to argue 
that both the internalist and externalist frameworks of justification are needed in order to arrive at a comprehensive account of epistemic justification in African epistemology.

The article is divided into four main sections. The next section argues for the necessity of an internalist orientation of justification in African epistemology. It is followed by a section which considers the rational grounds for traditional African beliefs in order to provide a rubric for the discourse on an internalist conception of epistemic justification in the traditional African context. Next, there is a section focusing on how metaphysical knowledge is acquired from a traditional African perspective that is essentially internalist. To further strengthen the central argument of the article, the fourth main section presents evidence for internalism in the epistemological perspectives of the Yoruba and Igbo cultures.

\section{The Necessity of Internalism in African Epistemology}

Internalism is the epistemological position which holds that factors that are relevant to the justification of knowledge-claims are within the epistemic agent. There are two senses in which internality is discussed by the internalist. The first connotes epistemic responsibility on the part of the epistemic agent to be aware of the reasonable grounds for any knowledgeclaim held. The "internal", in this sense, is that to which one has introspective access: it includes beliefs, as well as visual and other sensory impressions. To have such access to something is to be aware of it or to be able, through self consciousness or at least by introspective reflection, to become aware of it (Audi 1989, 309). The second sense of internality has to do with a theory of justification which requires that all of the factors needed for a belief to be epistemically justified for a given person are cognitively accessible to that person, that is, within his or her cognitive perspective (Bonjour 2010, 364).

Although there are many different versions of internalism, almost all internalists agree that their general position is supported by a "responsibilist" conception of epistemic justification. Internalists hold that epistemically justified belief is epistemically responsible belief, but since epistemic responsibility is a function of considerations internal to the believing subject, epistemic justification is also a function of such internal considerations (Greco 1990, 245). This probably explains why Pollock (1999) maintains that internalism in epistemology is the view that the internal states of the cognizers is relevant in determining which of the cognizers' beliefs are justified. 
Following from the basic tenet of the internalist conception of epistemic justification, I now wish to stress the need for an internalist framework of justification in African epistemology. To a large extent, African epistemology is connected with African metaphysics. This is hardly surprising, since epistemology deals with the nature and limits of human knowledge and therefore ideally includes metaphysical knowledge, especially when we talk about the conception of reality holistically rather than piecemeal. From the perspective of African culture, reality is not confined to the physical realm; rather, it comprises both the physical and the metaphysical, or the natural and the supernatural. For instance, the Yoruba conceive reality as that which fundamentally emanates from Olodumare - the arch divinity who is thought to exist eternally. It is from him that all things that are enter into being, and it is he who determines the essence of a being. As Bolaji Idowu observes, within the Yoruba cultural parlance, "Olodumare is the origin and ground of all that is" (Idowu 1962, 17). It is a fact which impresses itself on the advocates of Yoruba culture, and Yoruba religion in particular. The interesting thing about this architecture of rational belief is that it is appropriated through introspection and reasoning, and those who share this cultural background come to accept such facts as reasonable grounds for belief in and reverence for Olodumare.

Now, going by the dictates of the internalist theory of justification, all that is needed in order to justify a knowledge-claim is to determine whether the individual who claims to know, for instance, that "Olodumare is the ground of all being" has cognitive access to this belief, and whether or not the conditions that validate such a belief are located within the knowing subject. Alston (1989) lends credence to this submission in his assertion that what confers justification must be "internal" to the subject in that he or she must have a direct cognitive access to it: "It must consist of something like a belief or an experience, something that the subject can typically spot just by turning her attention to the matter" (Alston 1989, 5). Beliefs that are held in the manner outlined above are numerous in most African cultures, and they represent the internalist aspect of conceptions of knowledge in African thought.

Those who are sympathetic to the externalist orientation of justification might be opposed to the position being advanced in this article. Within the discourse on African epistemology, the externalist notion of justification has been advanced by Udefi (2009), Jimoh (1999), Aigbodioh (1997) and Njoku (2000), among others. Such scholars can be seen as taking the metaphysical approach to knowledge in African thought for granted. The predominant conclusion of the externalist interpretation of justification in African epistemology is that the 
phenomenon of human knowledge in African thought can be explained either from the contextualist or neo-positivist standpoints. The contextualist notion of justification holds that we should see our knowledge claims as situated within social milieu, so that we should not think of knowledge, truth and rational certainty in abstract terms (Jimoh 1999, 37). On its part, the neo-positivist notion of justification in African epistemology claims that knowledge is essentially dependent on empirical factors such as sense-experience or sensory perception (Hallen and Sodipo 1986). Both epistemic positions are immersed in the externalist orientation of justification. The problem with this orientation is that it does not account for those aspects of the African worldview expressed in oral traditions and existential relations, and, as such, does not give a full picture of how Africans apprehend reality in general.

Yet the life experiences of African people are multi-dimensional, revealing the nature of reality to African people in ways that are subject to plural interpretations. In this process of interpretation, references are often made to realities that transcend the physical, and the senses alone cannot fully apprehend the nature of such realities. Nevertheless, the need to apprehend these realities lies at the very heart of the African worldview, and yet this aspect of the African worldview cannot be captured by the externalist mode of explanation.

Furthermore, African metaphysical beliefs are rooted in an understanding appropriated from everyday experience of the universe; and its articulation is made possible through a process of rational belief-formation and introspective awareness consistent with the internalist perspective of knowledge acquisition. At the base of the internalist notion of justification is the assumption that knowledge is an individual thing because it starts with the self in terms of rational cognition. It is this rationalist aspect of African thought that we aim to underscore through this internalist interpretation of justification in African epistemology.

\section{The Rational Basis of Traditional African Beliefs}

By "rational basis of beliefs", we refer to those areas of thought that are shrouded in a metaphysical and non-material understanding of reality such that the grounds offered as justification of such beliefs are more internal than external. A basic concern of epistemology is to determine the conditions that render beliefs justified. Since justification has to do with the requirement that we give adequate reasons for the beliefs that we hold, this section seeks to illustrate the consistency of the rational basis of traditional African beliefs with the 
internalist notion of justification. The internalist notion of justification asserts that a belief can be accorded the status of knowledge if the epistemic agent holding it has some form of awareness of the rational grounds for regarding it to be true.

Rational thinking is present in the epistemic categories of the African people. There is no doubt that a great number of beliefs and practices are to be found in any African society (Mbiti 1969, 3). However, our epistemic exploration here does not in any way suggest that all of the beliefs held within any African cultural framework are rationally constructed: there are other beliefs that are not developed through pure rational inquest or introspection. Sometimes a belief is formulated to explain observable natural processes, as in the instance of the belief that having a good rainy season results in a bountiful harvest.

Our exposition of the rational basis of African beliefs is informed by the internalist perspective which requires that a person have some form of cognitive grasp of whatever makes his or her belief justified. The sense of "internal" here entails the use of the mind to comprehend reality independent of the empirical windows (five senses) through which knowledge about the physical world is derived. Indeed, within the purview of African culture, knowledge is not only a product of external or empirical conditions of justification, but also a matter of the agent's perspective.

Our interest in the exploration of the fabric of the African belief-system is to show, contrary to what the advocates of the externalist account of justification in African epistemology would have us believe, that beliefs can pass as knowledge in so far as the epistemic agent has some rational grounds for thinking that the beliefs are true. With reference to traditional African thought, many beliefs are regarded, on rational grounds, as not only true, but also as constituting indubitable grounds for knowledge. A good example of this is belief in the existence of gods and other spirit beings in African religion. The spiritual world plays a crucial role in African life for the reason that not every aspect of reality can be interpreted in purely physical terms. According to Mbiti $(1969,75)$, the spirits in general belong to the mode of existence between God and humans. Mbiti's assertion presupposes the dynamic nature of the African belief in the metaphysical reality of the spiritual world. In this regard, he further observes:

The spiritual world of African peoples is very densely populated with spiritual beings and the living-dead. Their insight of spiritual realities, whether absolute or apparent, is extremely sharp. To understand their religious ethos and 
philosophical perception it is essential to consider their concepts of the spiritual world in relation to the concepts of God. We have repeatedly emphasized that the spiritual universe is a unit with the physical, and that these two intermingle and dovetail into each other so much that it is not easy, or even necessary, at times to draw the distinction (Mbiti 1969, 75).

Thus belief in the spirit world is exceedingly strong in traditional Africa, and carries with it a profound conviction regarding the existence of a metaphysical realm.

However, the African belief in spirits and other metaphysical beings is not based on neopositivist evidence, but rather on rational evidence. For instance, the African belief in the reality of the gods probably stems from the manifest finitude of the human person, as well as from certain overwhelming circumstances in the universe that are not caused by humans. That Africans hold such a belief as an item of knowledge indicates that not all knowledgeclaims within African culture need to be validated by external means.

\section{The Significance of African Metaphysical beliefs}

In a bid to highlight the internalist aspects of epistemological conceptions in African thought, we now delve into the fabric of African metaphysics. We have adopted this approach because there can be no adequate appreciation of epistemic justification in African thought without bearing in mind that Africans conceive reality holistically. When we are talking about the notion of reality, we are implicitly referring to the notion of being - what is. Yet in considering the question of what there is, one also needs to address the question of how one knows what there is. This suggests that there is a connection between metaphysics and epistemology - a link that is evident in African thought.

In a general sense, metaphysics investigates reality in a bid to uncover the most fundamental contents of being as being. This explains why it is mostly considered as a kind of systematic study of being or reality as it is rather than as it appears. Aristotle describes it as the study of "being qua being" or an attempt to understand the transcendental nature of being as it is (Aristotle 1956, Book E 1065 26). Accordingly, a people's worldview should include their holistic conception of ultimate reality rather than a mitigated conception of being. The thrust of the discourse on African metaphysics is the African religious outlook. In fact, it would be difficult to separate African religion from African metaphysics. As Mbiti $(1969,7)$ correctly observes, from the perspective of Africans, the whole of reality, which is the sphere of metaphysics, is coloured by religion: from the beginning of a person's life to its end and even beyond death, Africans have religious interpretations for each situation. Hence, ontology to 
the Africans is a religious ontology: it is an ontology that has its foundations in the idea of "life-force", or "vital force". In fact, for Placide Tempels, force in African thought is inextricably bound up with being, that is, Africans do not separate being from force as its attribute; rather, they speak, act, live, as if for them being is force - force for them is the nature of being, force is being, being is force (Tempels 1959, 21).

Another significant feature of this metaphysical belief is that it offers a way of accounting for the non-material aspects of knowledge. However, we are not interested in an elaborate exposition of African metaphysics here; rather, we seek to examine how metaphysical beliefs are formed and the reasons offered for their justification, which in a way goes to show that Africans are capable of rational thinking in their knowledge-formation. The point being made here is that most African metaphysical beliefs are based on the types of evidence that can be referred to as "internalist", such that the knower has some rationally defendable convictions about the beliefs. This view is further strengthened by Conee and Feldman $(1985,25)$ in their discussion of epistemic justification, where they anticipate the internalist claim that a belief is justified only where the person has cognitive access to the evidence that supports the truth of the belief. This implies that all that is needed for the justification of African metaphysical beliefs is for the epistemic agents that claim to possess knowledge to be sure that they believe in certain entities, such as extra-terrestrial beings.

Furthermore, Innocent Onyewuenyi, in his writings on African epistemology, traces the foundation of knowledge to a divine realm, which presupposes the idea of rational cognition:

A person is said to know or have wisdom inasmuch as he approaches divine wisdom. One approaches divine knowledge when one's flesh becomes less fleshy, to use Leopold Senghor's expression, that is, the older a person gets, the more wisdom he has. The same note of hierarchy comes into play here. The ancestors have more wisdom, followed by the elders, dead or living. Distinction must be made here of the two levels of human intelligence. Intelligence can be either practical or habitual. Practical intelligence is cleverness, slyness in dealing with the contingent aspects of forces. Habitual intelligence is active knowledge of the nature of forces, their relationship. And this includes how man, the being with intelligence, makes use of things and activates the forces asleep in them. This kind of wisdom is different from book knowledge, which is not regarded as wisdom in the strict traditional sense (Onyewuenyi 1976, 525). 
Onyewuenyi underscores an important point which should be given more consideration, namely, the fact that one's ancestors are regarded as possessing wisdom. No matter how uncritical this statement appears to be, it does not repudiate the fact that this kind of belief is held in African culture. In so far as there are reasonable grounds offered for their cognition and articulation, the internalist requires us to pay attention to those rational grounds. One of the rational grounds that can be offered for the ascription of wisdom to dead relatives is the belief that those who died at old age would have accumulated much wisdom over many years, and that such wisdom ought to be shared with the living for the purpose of guidance.

The African metaphysical understanding, especially its emphasis on the concept of being, is deeply rooted in a system of a priori epistemological conceptions. This is corroborated by Okoro's description of the African metaphysical system as one which regards spirit, force, life-force, or vital-force as the primordial principle which permeates all things and is responsible for unity in diversity (Okoro 2011, 4). The African worldview also includes belief in the living-dead, ancestors and spirits (Ogungbemi 1997, 45). All of these metaphysical beliefs are rationally constructed in line with Wedgwood's conception of the rationality of a belief as something which purely relies on "internal facts" about the thinker's mental state (Wedgwood 2002, 349).

\section{Internalism in Yoruba and Igbo Thought}

In this section, we examine the epistemological perspectives of Yoruba and Igbo thought systems in order to correctly situate our discourse on the internalist conception of justification in African epistemology.

\section{Internalism From the Yoruba Epistemological Perspective}

According to Hallen and Sodipo (1986, 60), for the Yoruba, knowledge is derived from firsthand experience of the physical world through the sense of sight. However, this position is a faulty one since it does not consider the fact that the Yoruba conceive of reality as including that which transcends the physical world. There are many beliefs that the Yoruba hold that are not derived from firsthand sense-experience, and that are nonetheless regarded as knowledge. A good example of these is the Yoruba belief that one's success or failure in life has a lot to do with one's destiny which is derived from Olodumare (God in Yoruba belief). Indeed, they believe that a person's course of life has been predestined by 
Olodumare. To the Yoruba, the end for which a person is created is inextricably bound up with his or her destiny (Idowu 1962, 179).

Another piece of evidence for an internalist perspective of epistemic justification within the Yoruba cultural purview is the belief in the after-life: the rational explanation the Yoruba offer as the condition for an individual to live after death is moral uprightness:

Death is not the end of life. It is only a means whereby the present earthly existence is changed for another. After death, therefore, man passes, into a 'life beyond' which is called Ehin-Iwa - 'After-Life. This Ehin-Iwa is of vital importance than the present life, however prosperous this one may have been. The Yoruba thus speak of Ehin-Iwa ti I segbon Oni - 'After-Life' which is the superior of Today (the present). Whatever is done in the present life, therefore must be done with due regard to this great future: Nitori Ehin Iwa l'a se $n$ se oni l' oore - 'It is on account of After-Life that we treat Today hospitably (that we make a good use of the present and do not abuse it). In After-Life, those who have finished here go on living (Idowu 1962, 204).

The Yoruba strongly hold these beliefs, and yet they are not based on any positivist criterion for justification. The reasons behind these beliefs often have a religious orientation, and the people seldom question their veracity, mainly because such beliefs are connected to their cultural roots. The basis for regarding such beliefs as knowledge is consistent with the internalist criterion for justification, namely, that an epistemic agent should have some reasonable grounds for regarding his or her beliefs as true and as thereby constituting knowledge, and that such items of knowledge (gained through intuition or reflection) should be cognitively available to the knower. It would be pointless to try to convince the Yoruba to accept the position of Hallen and Sodipo that such beliefs are not knowledge because they lack the status of firsthand empirical verification. Thus for the Yoruba, knowledge cannot be limited to the physical world - it transcends the physical world to include the comprehension of metaphysical reality. This view is aptly supported by Washington $(2010,6)$ in his observation that "in traditional African world-view one's vision is not necessarily limited to the range of one's physical eyesight. Human beings can be endowed with spiritual vision. What the Yoruba refer to as ori-inu (inner eyes) and what others call the third eye is the source of spiritual vision".

Yet another piece of evidence for internalism from the Yoruba epistemological perspective is the postulation of eri-okan (the witness of the perceiver's okon, that is, his heart, mind or 
apprehension), which Hallen and Sodipo incorrectly interpreted as the validating criterion of empirically derived knowledge. According to the epistemological analysis provided by Hallen and Sodipo (1986), eri-okan is that which validates the empirical beliefs derived from the external world. Thus if one claims to see that what is in the room is a chair rather than a cupboard, it is one's eri-okan or witnessing of the mind that would support one's claim that what one sees is a chair and not something else. This is why Hallen and Sodipo $(1986,61)$ describe eri-okan as "your mind witnessing something 'for' or 'to' you", indicating self consciousness; But it also indicates comprehension and judgement (Hallen and Sodipo 1986, 61). It is important to note that eri-okan is an internalist criterion for the justification of knowledge, even though Hallen and Sodipo (1986) failed to see it as such. It indicates cognitive validation of a belief derived from empirical perception. For instance, if one believes that what one sees is a table rather than a tree, it is at the cognitive level that one can distinguish between conflicting perceptual experiences. Eri-okan is an affirmation of the fact that the epistemic agent has cognitive access to the beliefs that form the basis of his or her knowledge. Consequently, the eri-okan is evidence of internalism in the Yoruba epistemological framework.

\section{Internalism from the Igbo Epistemological Perspective}

The Igbo cultural perspective holds that knowledge is restricted neither to empirically verifiable claims, nor to contextualist notions of justification. The Igbo epistemological conception also transcends the physical order of things by including the metaphysical dimension. The term omenala, that is, "inherited patterns of thought" (Edeh 1985, 59), depicts the Igbo conceptualization of life (Ojike 1955, 150). Nwala (1985) provides us with a clear description of how this term functions in Igbo thought:

\footnotetext{
omenala, ..., refers to what accords to the basic beliefs and mores without which, in fact, as the igbo expresses it, the community would cease to exist because it must have lost touch with reality and the source of their existence. It does refer to the ideological expression of their economic, social, religious and political practice. It is that which also regulates their social practice (Nwala 1985, 27).
}

Thus Omenala includes major Igbo beliefs about the origin and nature of the universe, the place of the spirits, deities, humans and other beings in it, as well as the nature of prescriptions and prohibitions in such a universe. Thus it is evident that for the Igbo, reality is not limited to the physical world, and the validation of knowledge can therefore not be limited to external means. 
Furthermore, from the Igbo epistemological perspective, it is possible for one to derive knowledge from the information provided by other persons, even if one does not empirically see the phenomenon in question for oneself. What is important is that the source of the information is trustworthy. This kind of knowledge is what is referred to as amamife - the totality of all that a person knows. Knowing therefore is regarded as the ability to recognize what a person has encountered before, and involves the interaction of a person with his or her environment. Thus amamife is a representation or account of the facts in the world for which we have good reasons to accept as true, and that we are able to explain to other people (Udefi 1999, 151). The representation referred to here is cognitive information which is communicated to other epistemic agents within the social whole.

In addition, the Igbo hold that apart from knowledge derived from interaction with the environment, there is also the metaphysical dimension of knowledge, expressed in the doctrine of the after-life and the existence of spirit beings. This, in a way, explains why Igbo philosophy is coloured by its ontology which emphasizes belief in the spiritual nature of things, and a type of cosmic harmony in which humans and their actions are central, with supernatural powers superintending.

African thought, Igbo thought included, holds that created beings preserve an intimate ontological relationship with one another (Onyewuenyi 1979, 524). This ontological relationship is made possible by a rational understanding of the world of spirit beings. These spirit beings are believed to feature prominently in the lives of individuals and of the society at large. Indeed, it requires a level of reflection and a capacity for abstraction to conceive of a metaphysical system such as the one held by the Igbo. What this implies is that from the Igbo cultural perspective, there is room for non-physical realities that are conceived through the use of reason. That this kind of abstract thinking is communicated between people who share this cultural understanding is evidence of some level of cognitive awareness by the epistemic agents involved. Thus the Igbo metaphysical system points to an internalist perspective of epistemic justification.

By the same token, it is important to emphasise that the two conditions of knowledge put forward by advocates of an externalist orientation of justification in African epistemology, namely, direct sense perception and testimony, do not exhaust the sources of knowledge in traditional Igbo thought. The Igbo also give credence to inductive reasoning, which is often ignored in the treatment of African thought. Undoubtedly, perception or what is empirically 
observable constitutes one of the means of verifying knowledge among the Igbo, but this is not all that there is to the validation of knowledge in this community. For the Igbo, what is experienced is known in a firsthand manner. Thus they may say "nkaa bu ewu ojii (this is a black goat)." They may regard such knowledge as reliable but not infallible, because they know that our senses do not guarantee absolute certainty of what we claim to know (Udefi 1999, 157). Thus for the Igbo, beliefs acquired or derived from the senses constitute a necessary but not sufficient source of knowledge, because the human mind (apka uche) has an even greater role to play in knowledge validation.

The point here is that the human mind is not merely a passive receptacle of knowledge, but an active participant in the acquisition of knowledge. The situation here is simple: what one perceives (through the senses) is later processed and perhaps retained by the mind, thereby making it possible for the person to recollect what was previously presented to him or her, and this seems to guarantee the continued existence of physical objects even when they are not being perceived. This seems to be the case when the Igbo say " $k a$ mu chete ife' $m$ huru (Let me remember or recollect what I saw)" (Udefi 1999, 158). The mental aspect of knowledge acquisition emphasised here is quite instructive, as it substantiates, to an extent, the internalist notion of epistemic justification which holds that the mental state of the epistemic agent is crucial to the task of epistemic justification.

Apart from the Yoruba and Igbo cultural perspectives examined in this section, there are numerous African cultures that hold strong beliefs about metaphysical realities such as the after-life, spirits, and the divinities and God's associates. Belief in the spirits of the dead forms a crucial part of the rubric of the African worldview. Crispinous Iteyo, who has attempted a philosophical interpretation of beliefs in the spirits of the dead in Africa with a view to identifying rational grounds for accepting them, writes:

There is the conception of the world of spirits. The categories of spiritual beings in this world differ from one thought system to the other. Nevertheless, it is apparent that there is the category of God or the Supreme Being, and then the category of "other spirits", that is, ancestral spirits and/or "the spirits of the dead". Spirits are believed to have more power than humans, but have less power than God. Some may be seen as having places of abode, while others seem to wander the wilderness. Because they have more power than humans, they are capable of diminishing or increasing human power. To avoid the diminishing and to enhance the increment of power, humans placate them through prayer or other practices such as naming the newborn after departed relatives, or burying the dead with pomp and funfair (Iteyo 2009, 157). 


\section{Conclusion}

We have sought to highlight the fact that it is inappropriate for a discourse on what constitutes knowledge within African culture to exclude a discussion of the rational aspects of belief-formation and belief-acquisition. Towards this end, we have endeavoured to illustrate that along with the externalist approach to epistemic justification, traditional African thought recognises other means of validating knowledge, chiefly the internalist perspective. Drawing insights from some ethno-linguistic units in Africa, we have tried to show that Africans are capable of arriving at knowledge through non-empirical means, especially knowledge by means of reflection - knowledge one achieves merely by thinking about a given phenomenon or any particular matter at hand. Reflection is often aimed at understanding the world and humankind's place in it, which often leads to the construction of belief systems that account for the human person's relationship with the trans-physical world, spiritual beings, and other supernatural realities. As Bakari (1997, 2) observes, African epistemology involves a view of the world through a spiritual lens.

As is evident from our examination of the Yoruba and Igbo epistemological perspectives, beliefs are a very important feature of African culture, greatly influencing human behaviour. They are handed down from one generation to the other, sometimes with modifications. As such, to dismiss beliefs as a human category of thought that cannot qualify as knowledge is quite inappropriate. This is the major reason why the attempt to restrict the concept of knowledge to empirical data as is done by advocates of neo-positivism and by supporters of contextualist notions of justification in African epistemology should be re-examined. As the foregoing reflections have illustrated, there are numerous beliefs and epistemological predispositions in indigenous African culture that are more compatible with the internalist notion of epistemic justification than with the externalist one. This internalist interpretation of knowledge justification has been the missing link in the present discourse on African epistemology which this article has attempted to address. 


\section{References}

Aigbodioh, Jack. 1997. "Imperatives of Human Knowledge illustrated with Epistemological Conceptions in African Thought". Ibadan Journal of Humanistic Studies, Vol.7, pp.17-34.

Alston, William. 1989. Epistemic Justification. Ithaca: Cornell University Press.

Aristotle. 1956. Metaphysics. John Warrington ed. London: J.M. Dent \& Sons Ltd.

Audi, Robert. 1989. "Causal Internalism”. American Philosophical Quarterly,Vol.26 No.4, October, 1989,pp.309-320. http://www.jstor.org/stable/20014299

Bakari, R.S. 2012. 'Epistemology from an afrocentric perspective: enhancing black students' consciousness through an afrocentric way of knowing". Different Perspectives on Majority Rule, Paper 20, pp.1-4. http://www.farafinainstitute.org/attachments/article/119/Philosophical\%20foundation\%20of\%20knowled ge\%20creation $\% 20$ on $\% 20$ Africa.pdf

Bonjour, Laurence. 2010. "Externalism/Internalism". In Dancy, Jonathan, Matthias Steup and Ernest Sosa eds. 1992. A Companion to Epistemology, 2nd Ed. Oxford: WileyBlackwell, pp.364-368.

Conee, Earl and Richard Feldman. 1985. "Evidentialism". Philosophical Studies, Vol.17 No.15, pp.213-221. http://joelvelasco.net/teaching/4330/feldmanconee85evidentialism.pdf

Edeh, Emmanuel. 1985. Towards an Igbo Metaphysics. Chicago: Loyola University Press.

Greco, John. 1990. "Internalism and epistemically responsible belief”. Synthese, Vol.85 No.2, pp.245-277. http://fitelson.org/epistemology/greco.pdf

Hallen, Barry and Olubi Sodipo. 1986. Knowledge, Belief and Witchcraft: Analytical Experiments in African Philosophy. London: Ethnographica.

Idowu, Bolaji. 1962. Olodumare: God in the Yoruba belief. Ibadan: Longman Nigeria Plc.

Iteyo, Crispinous. 2009. "Beliefs in the Spirits of the Dead in Africa: a Philosophical Interpretation". Thought and Practice: A Journal of the Philosophical Association of Kenya, Vol.1 No.1, pp.147-159. www.ajol.info/index.php/tp/article/viewFile/46312/32710

Jimoh, Anselm. 1999. "Context-dependency of Human Knowledge: Justification of an African Epistemology”. West African Journal of Philosophical Studies, Vol.2 No.1, pp.18-39.

Kim, Kihyeon. 1993. "Internalism and Externalism in Epistemology". American Philosophical Quarterly, Vol.30 No.4, p. 308. www.jstor.org/stable/20014469

Marvan, Thomas. Ed. 2006. What Determines Content? Internalism/Externalism Dispute. New Castle: Cambridge Scholars Press.

Mbiti, John S. 1969. African Religions and Philosophy. London: Heinemann Educational Books.

Njoku, Francis. 2000. "Rorty on Post Philosophical Culture: Shaping our Culture without Thoughts". West African Journal of Philosophical Studies, Vol.3 No.1, pp.88-110.

Nwala, T.U. 1985. Igbo Philosophy. Lagos: Lantern Books. 
Ogungbemi, Segun. 1997. A Critique of African Beliefs. Lagos: Pumark Publishers.

Ojike, M.M. 1955. My Africa. London: Blandford Publications.

Okoro,Chiedozie. 2011. "The Notion of Integrative Metaphysics and its relevance to Contemporary World Order”. Integrative Humanism Journal, Vol.1 No.2, September 2011, pp.1-20.

http://www.academia.edu/1831628INTEGRATIVE_HUMANISM_JOURNAL 8

Onyewuenyi, Innocent C. 1976. "Is there an African philosophy?" Journal of African Studies, Vol.3 No.4, pp.513-528.

Pollock, John. 1999. “At the interface of Philosophy and AI”. Greco, John and Ernest Sosa eds. 1999. The Blackwell Guide to Epistemology. Malden: Blackwell, pp.383-414.

Sosa, Ernest. 1991. "Between Internalism and Externalism". Philosophical Issues, Vol.1, P.182.

Tempels, Placide. 1959. Bantu Philosophy. Paris: Presence Africaine.

Udefi, Amaechi. 1999. "A Critique of the Idea of African Epistemology". Unpublished Ph.D. Thesis, University of Ibadan.

--. 2009. "Rorty's Neopragmatism and the imperative of the Discourse of African Epistemology". Human Affairs, Vol.19, pp.78-86.

Washington, T.N. 2010. "Nickels in the nation sack: Continuity in Africana spiritual technologies". The Journal of Pan African Studies, Vol.3 No.5, pp.5-28.

Wedgwood, R. 2002. "Internalism Explained". Philosophy and Phenomenological Research, Vol.65 No.2, pp.349-369. 